\title{
Effect of pretreatment temperature on the surface modification of diatomite with trimethylchlorosilane
}

\author{
Allen Puente-Urbina ${ }^{1,3} \cdot$ Julia Hollenbach $^{2}$ Isaac F. Céspedes-Camachoo ${ }^{2,3}$. \\ Jörg Matysik $^{2}$ - Grettel Valle-Bourrouet ${ }^{1}$
}

Published online: 2 June 2016

(C) Springer Science+Business Media New York 2016

\begin{abstract}
Diatomite samples from Costa Rica were purified using acidic treatments with hydrochloric acid, thermally treated $\left(400-1000{ }^{\circ} \mathrm{C}\right)$ and then silylated with trimethylchlorosilane in toluene under inert atmosphere. The purification process allows to decrease the concentration of metals presented in the crude diatomite, as is confirmed by X-ray Fluorescence (XRF) Analysis. The silylated materials were analyzed by using Hyperpolarized ${ }^{129} \mathrm{Xe}$ Nuclear Magnetic Resonance Spectroscopy (HP ${ }^{129} \mathrm{Xe}$ NMR), Fourier Transform Infrared Spectroscopy (FTIR), X-ray Diffraction (XRD), Scanning Electron Microscopy (SEM), Thermogravimetric Analysis (TGA), rehydration tests, and contact angle measurements. XRD measurements indicate that diatomite is mainly amorphous, but presents several crystalline phases (kaolinite, cristobalite, and quartz). Pretreatments at high temperatures cause changes in those crystalline phases, resulting in more amorphous materials. However, there is no difference in the overall structure of purified and thermally treated diatomite samples with respect to the silylation products. In addition, SEM measurements show no effect over the pore structure of the materials. On the other hand, TGA measurements and rehydration tests show lower losses of water for silylated materials prepared using higher pretreatment
\end{abstract}

Grettel Valle-Bourrouet

grettel.valle@ucr.ac.cr

1 Laboratorio de Investigación en Química Inorgánica, Escuela de Química, Universidad de Costa Rica,

San Pedro 11501-2060, Costa Rica

2 Institut für Analytische Chemie, Universität Leipzig, Linnéstr. 3, 04104 Leipzig, Germany

3 Present Address: Escuela de Química, Tecnológico de Costa Rica, Cartago 159-7050, Costa Rica temperatures. Moreover, HP ${ }^{129} \mathrm{Xe}$ NMR, FTIR, and contact angle measurements evidence a modification due to covalent attachment of $\mathrm{Si}\left(\mathrm{CH}_{3}\right)_{3}$-groups to the surface, which increases for higher pretreatment temperatures. The results provide valuable information about external factors that influence the surface modification of diatomite. This can be useful to control modifications that can be achieved in a similar way.

Keywords Diatomite - Thermal treatment - Surface silylation · Trimethylchlorosilane $\cdot \mathrm{HP}{ }^{129} \mathrm{Xe}$ NMR

\section{Introduction}

Diatomite, also known as diatomaceous earth and kieselgur, is a porous mineral that can be found in natural sediments. It is classified as a siliceous sedimentary rock, resulting from the accumulation and compaction of diatoms remains over geological time scales. The main mineral component is the frustules, the silicified hard shells of diatoms. These shells are composed of amorphous silica which is responsible for the high porosity, strong adsorbability, good thermal resistance, and chemical inertness of diatomite [1-3].

Diatomaceous earth is a greatly exploited mineral, reaching a world mine production of $2,120,000$ metric tons in 2012 [4]. It has been widely used as filter, adsorbent, remover of contaminants, mineral filler, abrasive, and catalytic support [5-9]. In Costa Rica, thirteen mineral deposits of diatomite were known to 1990 along the southwest slope of the Quaternary Volcanic Chain, in the region located between Liberia and Cartago [10]. These deposits are closely associated with the late Tertiary (Pliocene)-Quaternary acid-intermediate volcanism [11]. 
Between 2008 and 2011, Costa Rica produced 77,800 metric tons of diatomite, being one of the biggest producers in Latin America [12].

The surface of silica is composed of siloxane bridges and hydroxyl groups (i.e. silanols) [13, 14]. These silanol groups are important for several surface phenomena such as wetting, adsorption, and dispersion in liquid media [15]. Also, hydroxyl groups over silica surface are the essential reactive sites for surface modification [16].

There are several types of silanol groups. Their characteristics and distribution depend on the way in which they are attached to silicon atoms as well as external factors such as thermal treatment, environment moisture, and storage time [17, 18]. Thermal treatment, depending on the working temperature, can lead to surface removal of physically adsorbed water and dehydroxylation of vicinal hydroxyl groups. This treatment can be critical for further chemical modification considering the fact that isolated silanols are more reactive than siloxane bridges produced by dehydroxylation processes [19].

During the last decades, great attention has been paid to synthetic silica surface modification (e.g. by silylation) $[16,20-27]$. Fewer studies have been focused on surface modification of diatomaceous amorphous silica. However, significant research related with diatomite surface modification has focused on syntheses of materials such as water superabsorbent, conducting composites, removers of metal ions and organic contaminants from waters, superhydrophobic surfaces, and nanocarriers for drug delivery [28-36]. Even with that variety of possibilities, only few authors have studied the factors that control those modifications (e.g. acidic and thermal treatments) in order to obtain enhanced properties of the resulting materials [34-36].

Silica and diatomite have been studied using spectroscopic techniques such as IR [3, 15, 22, 37, 38], Raman $[3,39,40]$, and NMR (including ${ }^{1} \mathrm{H}$ and ${ }^{29} \mathrm{Si}$ analyses using solid-state NMR spectroscopy techniques $[17,20,38,40-44])$. Other works focused on surface modification [20, 45-48]. Nonetheless, there are very few reports about the effect of thermal pretreatment on the surface modification of diatomite [2, 34].

Here we present an analysis of the surface silylation of Costa Rican diatomite with trimethylchlorosilane (TMCS) using Hyperpolarized ${ }^{129} \mathrm{Xe}$ Nuclear Magnetic Resonance Spectroscopy (HP ${ }^{129} \mathrm{Xe}$ NMR), Fourier Transform Infrared Spectroscopy (FTIR), X-ray Diffraction (XRD), Thermogravimetric Analysis (TGA), Scanning Electron Microscopy (SEM), rehydration tests, and contact angle measurements of the pelletized materials. The aim of this work is to study the effect of the pretreatment temperature of the diatomite before silylation, in order to obtain useful information about factors that could influence and control that modification.

\section{Experimental}

\subsection{Samples preparation}

\subsubsection{Purification of diatomite}

Crude diatomite (CD) was obtained from the company Industrias Mineras S.A. (Barranca, Puntarenas, Costa Rica). The purification of the raw material is similar to the one proposed by Yuan and co-workers [2], with some modifications. The purification consists in four times acid-washing process. In each purification process, a mixture of diatomite and $2.0 \mathrm{M} \mathrm{HCl}$ solution was kept under reflux and stirring for $4 \mathrm{~h}$, using a proportion of $\mathrm{CD}$ to $\mathrm{HCl}$ solution of $1 \mathrm{~g}$ of diatomite to $15 \mathrm{~cm}^{3}$ of $2.0 \mathrm{M} \mathrm{HCl}$ solution. At the end of each acid treatment, the diatomite was centrifuged. Finally, at the end of the fourth acid-washing, the diatomite was centrifuged and washed copiously with water until free of $\mathrm{Cl}^{-}$(tested by $\mathrm{AgNO}_{3}$ ). Purified diatomite (PD) was dried at $70{ }^{\circ} \mathrm{C}$ for $24 \mathrm{~h}$ and stored in a sealed vessel.

\subsubsection{Thermal pretreatment of purified diatomite}

The pretreatment was performed by heating the samples under air in a muffle furnace for $1 \mathrm{~h}$ at the desired temperature. The following temperatures were used: 400,450 , $500,550,600,800$, and $1000{ }^{\circ} \mathrm{C}$. After the heating, the samples were kept in a desiccator under vacuum. The corresponding weight loss related with each heating process was measured using an analytical balance. The thermally treated samples are denoted as PD- $T$, with $T$ the temperature of thermal treatment in ${ }^{\circ} \mathrm{C}$ (e.g. PD-400 for the PD thermally treated at $400{ }^{\circ} \mathrm{C}$ ).

\subsubsection{Modification of purified diatomite with TMCS}

PD- $T$ samples were modified using TMCS. The modification processes were carried out under $\mathrm{N}_{2}(\mathrm{~g})$ atmosphere. A mass between 2.200 and $2.400 \mathrm{~g}$ of each PD- $T$ was dispersed on $15 \mathrm{~cm}^{3}$ of toluene previously dried over $\mathrm{Na} /$ benzophenone. After that, $3 \mathrm{~cm}^{3}$ of TMCS ( $\left.2.57 \mathrm{~g} ; 23.6 \mathrm{mmol}\right)$ were added. The reaction mixture was refluxed for $16 \mathrm{~h}$. The product was recovered by filtration, washed with water and acetone, and dried for $24 \mathrm{~h}$ at $105{ }^{\circ} \mathrm{C}$. The silylated samples are denoted as PD-T-M, with $T$ the temperature of thermal pretreatment in ${ }^{\circ} \mathrm{C}$ (e.g. PD-400-M for the PD thermally treated at $400{ }^{\circ} \mathrm{C}$ and then silylated with TMCS).

\subsubsection{Rehydration and drying of silylated samples}

PD- $T$-M samples were stored in non-sealed containers for several months under regular conditions in San Pedro de Montes de Oca, Costa Rica (topical climate, annual 
average temperature: $20.8{ }^{\circ} \mathrm{C}$ and relative humidity: $82.5 \%$, according to the National Meteorological Institute for the period 1999-2013). Then, the sample weight losses were recorded after 5 days of drying at $65{ }^{\circ} \mathrm{C}$.

\subsection{Characterization}

\subsubsection{Chemical composition}

Chemical compositions of $\mathrm{CD}$ and $\mathrm{PD}$ were determined by XRF analysis using a Ag source and an Amptek XR$100 \mathrm{CR}$ detector. The results were recorded without standard (i.e. assuming a composition of $100 \%$ ). The system was calibrated using $\mathrm{Ti}$ and Mo references.

\subsubsection{SEM}

The morphology of the samples were analyzed by SEM with a Hitachi Tabletop Microscope TM-1000. The samples were placed onto a conductive carbon tape and directly analyzed using an accelerating voltage of $15 \mathrm{kV}$.

\subsubsection{XRD}

X-ray powder diffraction data of the samples were acquired with a Bruker D8 Advance diffractometer with Cuk $\alpha 1-\mathrm{k} \alpha 2$ radiation. Each pattern was obtained in the $2 \theta$ range of $5.000-59.995^{\circ}$ with steps of $0.018^{\circ}$ and step times of $501 \mathrm{~s}$.

\subsubsection{Surface analysis}

The pore structural properties of the samples were determined by nitrogen adsorption using a Micromeritics Accelerated Surface Area and Porosimetry System 2010 (ASAP 2010). Before analysis, all the samples were activated at $90{ }^{\circ} \mathrm{C}$ under vacuum for $6-8 \mathrm{~h}$. The specific surface area was evaluated by using the Brunauer-EmmettTeller (BET) method in the relative pressure range $\left(\mathrm{p} / \mathrm{p}_{0}\right)$ of the sorption isotherm between 0.05 and 0.25 . A value of $0.162 \mathrm{~nm}^{2}$ per molecule was taken for the cross sectional area of a nitrogen molecule.

\subsubsection{FTIR}

The FTIR spectra of PD- $T$-M samples were recorded using a Varian 640-IR spectrometer. Samples were prepared by mixing $(2.3 \pm 0.1) \mathrm{mg}$ of each modified diatomite with $(146.0 \pm 0.1) \mathrm{mg}$ of $\mathrm{KBr}$ and pressing the mixture at 15,000 psi under vacuum for $5 \mathrm{~min}$. Each spectrum was obtained by averaging 64 scans in a wavenumber range of $2500-4000 \mathrm{~cm}^{-1}$ with a resolution of $0.5 \mathrm{~cm}^{-1}$.

\subsubsection{Contact angle measurements}

Contact angles of glycerin with the samples were determined using a Ramé-Hart Contact Angle Goniometer with DROPimage CA v2.5 for image analysis. The tested samples were dried at $65^{\circ} \mathrm{C}$ for 5 days before measuring, followed by pelletization of $(0.10 \pm 0.01) \mathrm{g}$ of each sample at 20,000 psi under vacuum for 5 min. $6 \mu \mathrm{L}$ drops of glycerin were used and the contact angles were recorded several times in different positions of the pellets.

\subsubsection{TGA}

TGA analyses were performed on a TA Instruments Q5000IR thermogravimetric analyzer. For all the experimental runs, around $10 \mathrm{mg}$ of sample were used. The heating range was from 40 to $1000{ }^{\circ} \mathrm{C}$ at a heating rate of $10{ }^{\circ} \mathrm{C}$ min $^{-1}$ under Ultra High Purity nitrogen atmosphere with flow rates of $25 \mathrm{~mL} \mathrm{~min}^{-1}$ in the sample and $10 \mathrm{~mL} \mathrm{~min}^{-1}$ in the balance.

\subsubsection{HP ${ }^{129} \mathrm{Xe} N M R$}

Several HP ${ }^{129} \mathrm{Xe}$ NMR spectroscopy techniques were used to analyze the modified diatomite samples. These included continuous flow measurements, variable temperature (VTNMR) experiments and ${ }^{129} \mathrm{Xe}-{ }^{129} \mathrm{Xe} 2 \mathrm{D}$ exchange spectroscopy (EXSY) analyses. All spectra were recorded with standard a BBO-probe on a Bruker DRX-400 spectrometer operating at $110.68 \mathrm{MHz}$ for ${ }^{129} \mathrm{Xe}$. The signal of the free gas was used for referencing the chemical shifts and therefore set to $0 \mathrm{ppm}$. The hyperpolarized $\mathrm{Xe}$ gas was produced in a home-built continuous-flow Xe-polarizer using a gas mixture consisting of $2.4 \% \mathrm{Xe}$ (natural isotopic portions), $9.6 \% \mathrm{~N}_{2}$ and $88 \% \mathrm{He}$. The optical pumping cell made of Pyrex contained $300 \mathrm{mg} \mathrm{Rb}$ (purity: $>99 \%$, AlfaAesar) and was operated at $145{ }^{\circ} \mathrm{C}$ and $3 \mathrm{bar}$ for the pumping process. The samples were dried at $60{ }^{\circ} \mathrm{C}$ for 5 days and then directly transferred into standard $5 \mathrm{~mm}$ o.d. NMR tubes with a home-designed gas insertion cap through which the HP-Xe gas mixture was continuously inserted during the measurement.

\section{Results and discussion}

The chemical compositions of $\mathrm{CD}$ and PD, determined by $\mathrm{XRF}$, are presented in Table 1. The data show $\mathrm{Si}$ as the main component of $\mathrm{CD}$ and $\mathrm{PD}$, as expected. However, there is a significant difference between the other components of the samples that can be attributed to the purification of the $\mathrm{CD}$ using four times acid-washing process with $\mathrm{HCl}$ (aq.). There is a decrease on the concentration of those 
Table 1 Chemical composition of crude diatomite (CD) and purified diatomite (PD)

\begin{tabular}{|c|c|c|c|c|}
\hline \multirow[t]{2}{*}{ Component } & \multicolumn{2}{|l|}{$\mathrm{CD}$} & \multicolumn{2}{|l|}{ PD } \\
\hline & wt $\%$ & $\mathrm{~mol} \%$ & $\mathrm{wt} \%$ & $\mathrm{~mol} \%$ \\
\hline $\mathrm{Si}$ & $77.491 \pm 1.232$ & 81.421 & $96.821 \pm 0.970$ & 92.664 \\
\hline $\mathrm{Al}$ & $11.282 \pm 1.692$ & 12.340 & $5.557 \pm 0.834$ & 5.536 \\
\hline $\mathrm{Ca}$ & $1.753 \pm 0.057$ & 1.291 & $1.214 \pm 0.042$ & 0.814 \\
\hline $\mathrm{Ti}$ & $1.397 \pm 0.028$ & 0.861 & $0.914 \pm 0.019$ & 0.513 \\
\hline $\mathrm{Fe}$ & $6.594 \pm 0.025$ & 3.485 & $0.459 \pm 0.007$ & 0.221 \\
\hline $\mathrm{Cu}$ & $0.122 \pm 0.005$ & 0.056 & $0.067 \pm 0.003$ & 0.028 \\
\hline $\mathrm{Zn}$ & $0.068 \pm 0.005$ & 0.031 & $0.044 \pm 0.003$ & 0.018 \\
\hline As & $0.051 \pm 0.005$ & 0.020 & $0.001 \pm 0.003$ & 0.000 \\
\hline $\mathrm{Cr}$ & $0.083 \pm 0.012$ & 0.047 & $0.112 \pm 0.008$ & 0.058 \\
\hline $\mathrm{Mn}$ & $0.073 \pm 0.009$ & 0.039 & $0.062 \pm 0.006$ & 0.030 \\
\hline $\mathrm{Sr}$ & $0.645 \pm 0.014$ & 0.217 & $0.020 \pm 0.007$ & 0.006 \\
\hline $\mathrm{Zr}$ & $0.240 \pm 0.022$ & 0.078 & $0.165 \pm 0.012$ & 0.049 \\
\hline $\mathrm{V}$ & $0.169 \pm 0.014$ & 0.098 & $0.102 \pm 0.011$ & 0.054 \\
\hline $\mathrm{Ni}$ & $0.031 \pm 0.006$ & 0.016 & $0.019 \pm 0.003$ & 0.009 \\
\hline
\end{tabular}

other components (except in $\mathrm{Cr}$ that does not present a statistically significant difference), including $\mathrm{Ca}, \mathrm{Ti}$ and $\mathrm{Fe}$, that together with $\mathrm{Si}$ represent 98.33 wt \% of $\mathrm{CD}$. The change of concentrations can be noted visually because of a whitish look of $\mathrm{PD}$ compared to $\mathrm{CD}$, suggesting a reduction of the presence of colored oxides (e.g. $\mathrm{Fe}_{2} \mathrm{O}_{3}$ ).

After the purification process, PD was thermally treated at different temperatures. Thermal treatment could generate surface changes in diatomite. Under normal conditions this material has water over its surface, consisting in a first coating of water $\mathrm{H}$-bonded with surface silanols, followed by physisorbed water molecules $[2,3]$. As the temperature increases, surface changes start with the loss of physisorbed water and water that is $\mathrm{H}$-bonded with surface silanols, resulting in the exposure of silanols that can be isolated or H-bonded together. After that, silanols can react between them, resulting in siloxane bridges. Measurements of the weight loss of PD after thermal treatments show an increment with higher temperatures (Fig. 1).

The silylation of silica and diatomaceous amorphous silica is a well-known process [2, 16, 20-29]. It proceeds as a reaction of surface silanols with the corresponding silane to form stable silicon-oxygen bonds. Modification of thermally treated PD samples was made with TMCS. TMCS reacts readily with silanols, producing $\mathrm{HCl}$ and forming a covalent attachment of $\mathrm{Si}\left(\mathrm{CH}_{3}\right)_{3}$-groups to the surface. The processes were carried out using appropriate laboratory techniques to ensure a reaction environment free of air and water. Such conditions are important to prevent TMCS hydrolysis as well as surface rehydration of the thermally treated PD.

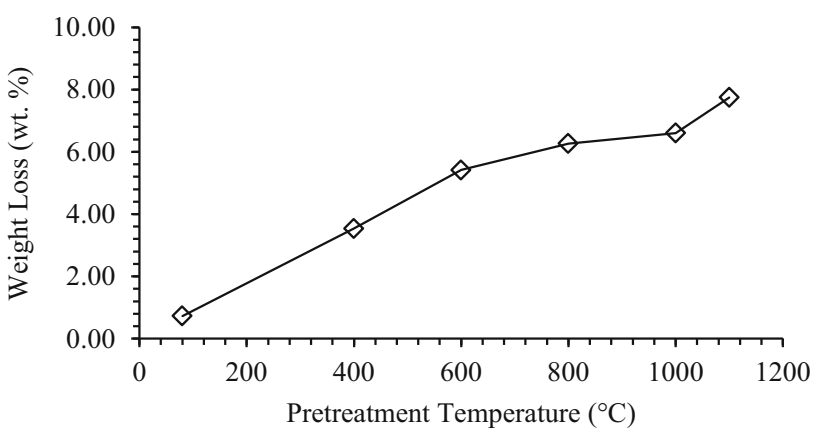

Fig. 1 Weight loss of PD after thermal treatments at different temperatures for $1 \mathrm{~h}$

In order to analyze the morphology and structure of the diatomite samples, SEM and XRD measurements were performed. SEM micrographs of PD are shown in Fig. 2. The typical microscopic structures presented remain unchanged when PD is thermally treated at different temperatures $\left(400-1000{ }^{\circ} \mathrm{C}\right)$ and also after silylation.

On the other hand, the XRD patterns of $\mathrm{CD}$ and $\mathrm{PD}$ (Fig. 3a, b) show a broad signal between $15^{\circ}$ and $30^{\circ}$ indicating that these samples are mainly composed of amorphous silica. Nevertheless, several crystalline phases can be clearly detected: kaolinite, cristobalite, and quartz.

Changes in the bulk structure of diatomite could be achieved in thermal treatments. For instance, Aderdour and co-workers mention sintering temperatures from $680{ }^{\circ} \mathrm{C}$ [49]. Other works report transitions between crystalline phases. Thongkasam's group describes the appearance of cristobalite from a diatomite mainly composed of quartz (CD from Lampang Province, Thailand) when it is treated at $1100{ }^{\circ} \mathrm{C}$ [50]. Lazutkina et al. [51] present the transition among $\beta$-quartz and $\alpha$-quartz in Irbitskii diatomite (Sverdlovsk Region, Russia) in the range of 610 and $800{ }^{\circ} \mathrm{C}$ and between 652 and $740{ }^{\circ} \mathrm{C}$ for Kamyshlovskii diatomite (Sverdlovsk Region, Russia). Another report done by Mohamedbakr and Burkitbaev, presents a change in crystalline phases as well as the formation of agglomerates or clusters through sintering when $\mathrm{CD}$ from Aktyubinsk (Kazakhstan) is thermally treated at $900{ }^{\circ} \mathrm{C}$ [52]. The XRD analyses of thermally treated samples show the same results as CD and PD for PD-400 (Fig. 3a-c). However, higher temperatures cause changes in the crystalline phases presented in $\mathrm{PD}$ and $\mathrm{CD}$, resulting in more amorphous materials (Fig. 3e, g, i). Moreover, XRD results show that thermally treated samples and their corresponding silylation products Fig. $3 \mathrm{c}-1$ present no significant difference in their overall structure. But, other analyses of the silylated materials show an actual modification, suggesting a surface modification.

As well as its structure and behavior under different thermal treatments, the origin of the diatomite influences 


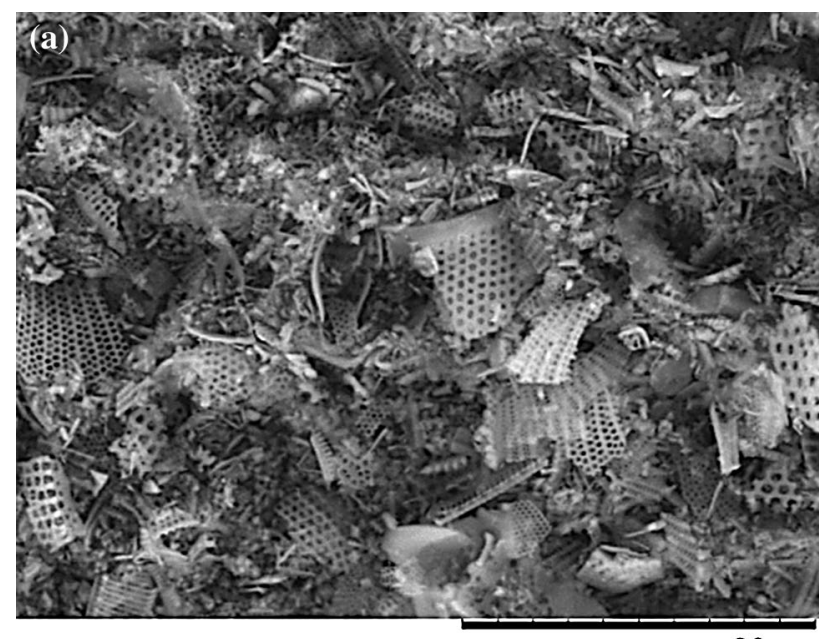

20 um

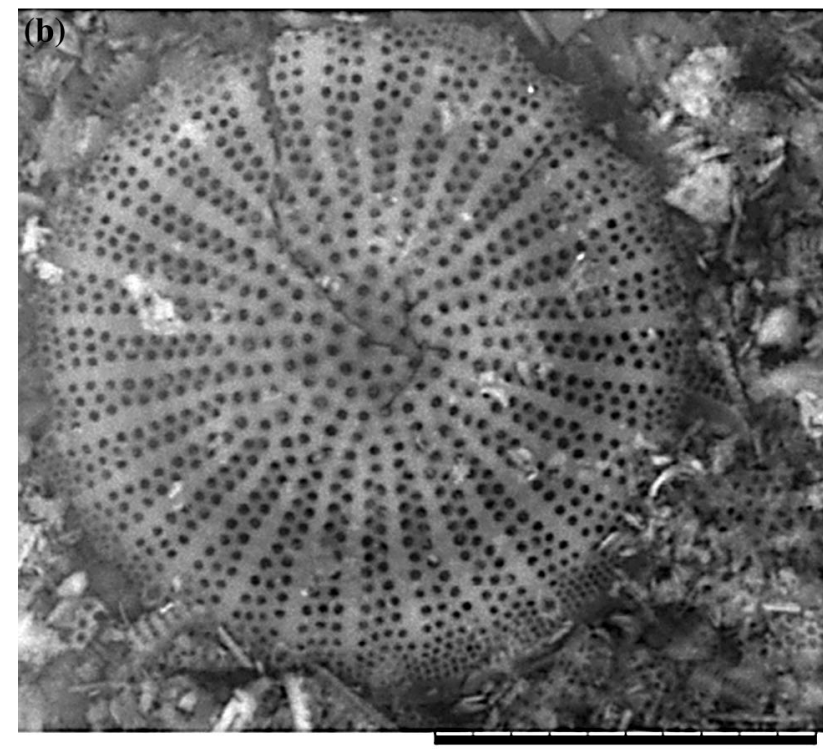

10 um

Fig. 2 SEM micrographs of PD

its surface characteristics. Literature presents a wide range of surface areas. That includes values of surface areas of raw diatomite from different deposits such as $3.81 \mathrm{~m}^{2} \mathrm{~g}^{-1}$ (Tainan, Taiwan [53]), $11.8 \mathrm{~m}^{2} \mathrm{~g}^{-1}$ (Zhejiang, China [3]), $14.0 \mathrm{~m}^{2} \mathrm{~g}^{-1}$ (Guangdong, China [3]), $17.12 \mathrm{~m}^{2} \mathrm{~g}^{-1}$ (Kolubara mine, Serbia [54]), $24.77 \mathrm{~m}^{2} \mathrm{~g}^{-1}$ (Nevada, USA [55]), $25.2 \mathrm{~m}^{2} \mathrm{~g}^{-1}$ (Jiling, China [32]), $33 \mathrm{~m}^{2} \mathrm{~g}^{-1}$ (Amman, Jordan [56]), $56.3 \mathrm{~m}^{2} \mathrm{~g}^{-1}$ (Guangdong, China [2]), and $189 \mathrm{~m}^{2} \mathrm{~g}^{-1}$ (Kütahya, Turkey [57]). Surface properties of $\mathrm{CD}$ and $\mathrm{PD}$ are shown in Table 2. The results show a clear decrease in $\mathrm{S}_{\mathrm{BET}}, \mathrm{V}_{\mathrm{P}}$, and $\mathrm{D}_{\mathrm{p}}$ of $\mathrm{PD}$ in comparison to CD. It is well known that the presence of metal oxides could increase the surface area of diatomite $[55,56]$. The purification process of $\mathrm{CD}$ removes metals that are present as oxides (e.g. $\mathrm{Fe}_{2} \mathrm{O}_{3}[6]$ ), leading to a decrease of the above mentioned surface properties of PD. In addition,
BET surface analysis of thermally treated PD samples showed that a $400{ }^{\circ} \mathrm{C}$ treatment does not affect aspects as $\mathrm{S}_{\mathrm{BET}}, \mathrm{V}_{\mathrm{p}}$, and $\mathrm{D}_{\mathrm{p}}$, but procedures at higher temperatures (e.g. $800{ }^{\circ} \mathrm{C}$ ) may cause a decline in those parameters.

The FTIR spectra of two silylated samples are shown in Fig. 4. The signals presented at 2963, 2920, and $2851 \mathrm{~cm}^{-1}$ are related to the vibrational modes of the TMCS grafted to the surface $[2,46,58,59]$. In the case of PD-400-M (Fig. 4a), its FTIR spectrum shows sharp signals between 3696 and $3621 \mathrm{~cm}^{-1}$ attributed to isolated hydroxyl groups, as well as broad signals related to H-bonded hydroxyl groups [3] and probably traces of water present in the salt used to disperse the material and to conduct the measurement (i.e. $\mathrm{KBr}$ ). The spectra obtained for the other PD-T-M samples show similar broad bands due to H-bonded hydroxyl groups and the probable presence of water because of the $\mathrm{KBr}$, but the sharp signals presented in the PD-400-M spectrum were not observed. This situation can be clearly seen in the spectrum showed in Fig. 4b, as an example of the other silylated samples. Thermal treatment first leads to removal of surface water (i.e. capping water and physisorbed water) resulting in exposure of more isolated silanols. With higher temperatures, dehydroxylation processes can occur. Considering that behavior and the fact that PD- $T$ samples were subjected to modification with TMCS, for PD-T-M samples with $T$ higher than $400{ }^{\circ} \mathrm{C}$, the absence of sharp signals related to isolated silanols in their FTIR spectra could be attributed to a combination of modification of the silanols remaning in the material after the thermal treatment and the collapse of other silanol during that thermal treatment to form siloxane bridges in dehydroxylation processes.

Rehydration tests, TGA, contact angle measurements, and HP ${ }^{129} \mathrm{Xe}$ NMR measurements were applied to study more in detail that silylation of the PD-T-M samples.

Considering the rehydration tests, the silylated samples were stored under normal conditions, in order to evaluate their capacity to capture water from the environment. The weight losses of these samples after a $65{ }^{\circ} \mathrm{C}$ treatment are presented in Fig. 5. The results show that the higher the pretreatment temperature before silylation, the lower the weight loss after the drying treatment. This trend indicates a lower rehydration capacity of the products with higher pretreatment temperatures before surface modification, resulting from a greater silylation that makes the surface more hydrophobic. The results are consistent with a previous report [2]. It is important to note that the thermal pretreatments of the PD samples before silylation lead to the removal of surface water. In addition, those thermal treatments were developed at temperatures high enough to also promote dehydroxylation processes. However, the trend found suggests that even with both processes occurring in the temperature range evaluated $\left(400-1000{ }^{\circ} \mathrm{C}\right)$, the 


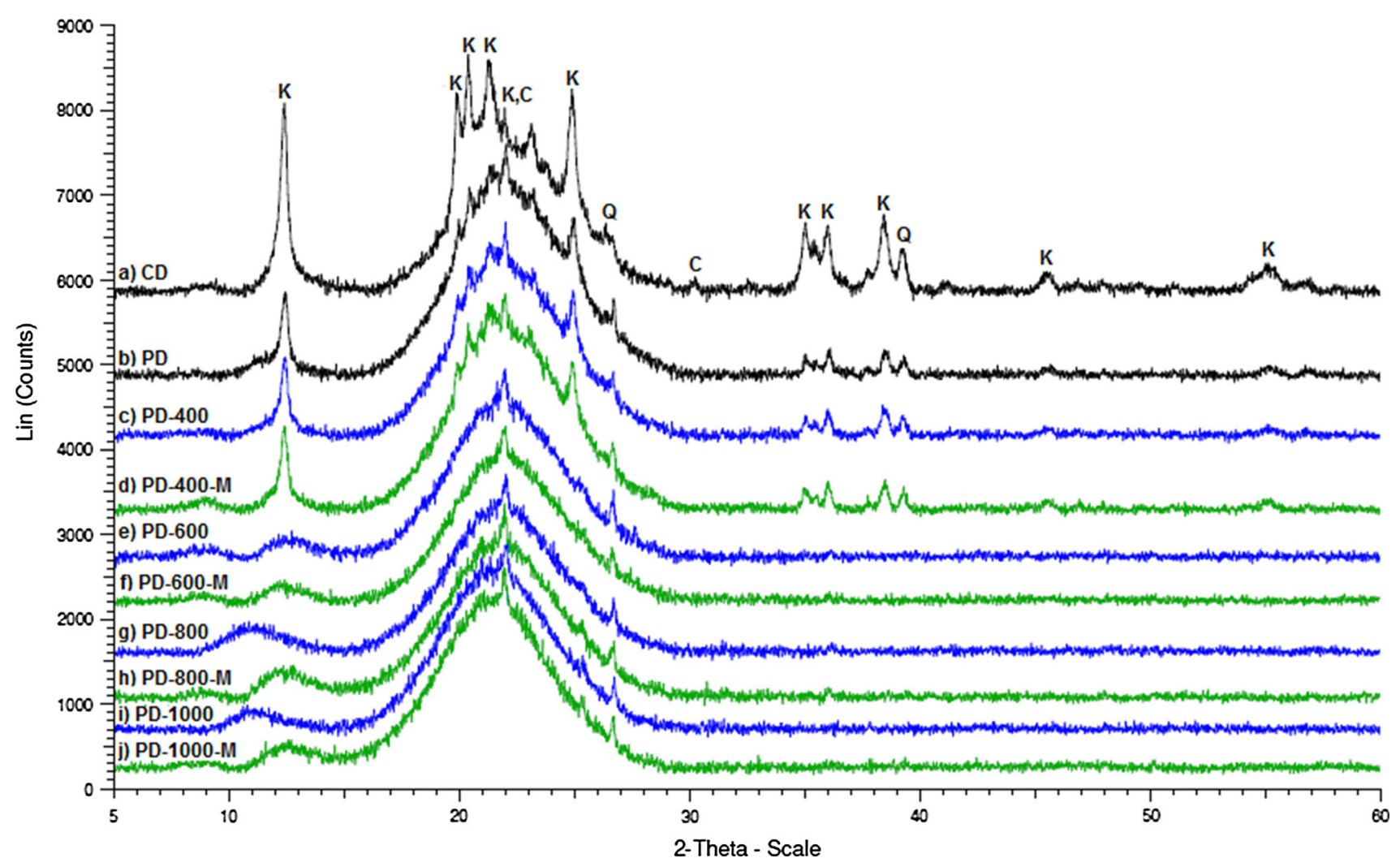

Fig. 3 XRD patterns of CD, PD, PD- $T$, and PD- $T$-M samples ( $K$ kaolinite, $C$ cristobalite, $Q$ quartz)

Table 2 Surface properties of diatomite samples

\begin{tabular}{llll}
\hline Sample & $\mathrm{S}_{\text {BET }}\left(\mathrm{m}^{2} \mathrm{~g}^{-1}\right)^{\mathrm{a}}$ & $\mathrm{V}_{\mathrm{P}}\left(\mathrm{cm}^{3} \mathrm{~g}^{-1}\right)^{\mathrm{b}}$ & $\mathrm{D}_{\mathrm{P}}(\mathrm{nm})^{\mathrm{c}}$ \\
\hline CD & 57 & 0.104 & 24 \\
PD & 33 & 0.069 & 13 \\
PD-400 & 35 & 0.069 & 16 \\
PD-400-M & 28 & 0.072 & 18 \\
PD-500-M & 27 & 0.070 & 17 \\
PD-600-M & 28 & 0.056 & 27 \\
PD-800 & 29 & 0.063 & 14 \\
\hline
\end{tabular}

${ }^{\text {a }}$ BET surface area

b Total pore volume

c Average pore diameter

higher the pretreatment temperature, the greater the amount of silanols that were available to be modified with TMCS, resulting in greater modifications for higher pretreatment temperatures.

The trend presented in Fig. 5 can be confirmed using TGA of the PD-T-M samples (Figs. 6, 7). The results are expressed in terms of the total weight loss of each silylated sample occurring in the corresponding TGA experiment, with water as the main component of these losses. TGA curves show that the greater decrease in the weight is because of the first event of water loss occurring at lower temperatures (i.e. mainly a surface water loss below $200{ }^{\circ} \mathrm{C}$, lower than the pretreatment temperatures), as evidence the ones related with the samples PD-400-M and PD-600-M, shown in Fig. 6 as an example of the silylated materials. Another event is presented around $400{ }^{\circ} \mathrm{C}$ due to dehydroxylation processes. This mass loss decreases with increasing pretreatment temperature and also is relatively small compared with the main mass loss occurring at lower temperatures. Consequently, the more significant amount of mass released during each TGA experiment will be due to the water that each PD-T-M can adsorb after the silylation process, and that capacity to adsorb water is dependent on the degree of silylation (i.e. how hydrophobic is the resulting material). As a result, the data presented in Fig. 7 show a greater silylation for higher pretreatment temperatures, supporting the trend previously shown in Fig. 5.

Considering the contact angle measurements, these were performed with glycerin drops over pelletized samples (Table 3; Fig. 8). The data obtained show a great enhancement of the contact angle for PD-T-M samples in contrast to the angle showed between glycerin and PD. That is a result of the presence of non-polar $\mathrm{Si}\left(\mathrm{CH}_{3}\right)_{3^{-}}$ 
(a)

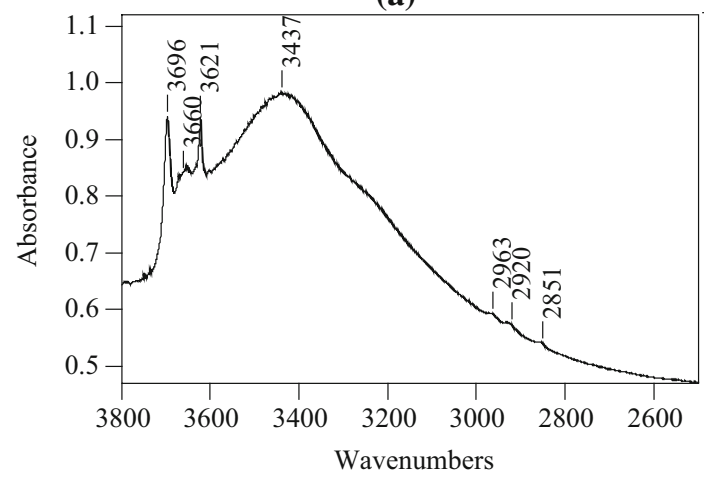

(b)

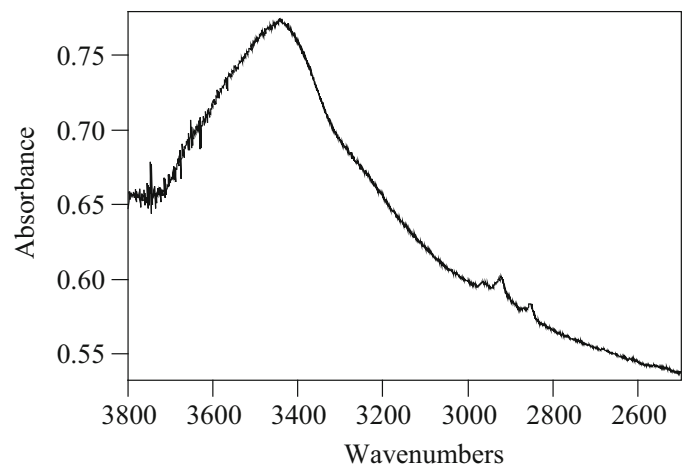

Fig. 4 FTIR spectra of two PD-T-M samples. a PD-400-M and b PD1000-M

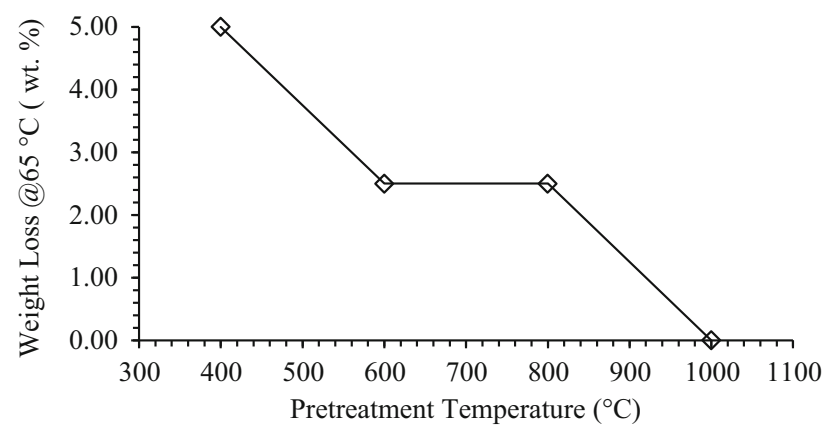

Fig. 5 Weight loss of PD-T-M samples after drying at $65{ }^{\circ} \mathrm{C}$

groups over the surface that decrease the affinity to the polar solvent used in the assays.

Finally we applied HP ${ }^{129} \mathrm{Xe}$ NMR to study the diatomite samples. HP ${ }^{129} \mathrm{Xe}$ NMR is a well established technique to study porous materials and surfaces that is based on the environmental sensitivity of the ${ }^{129} \mathrm{Xe}$ chemical shift. In general, the NMR parameters are affected by the interaction of the gas, the symmetry of the voids and also the motion of the gas inside the material. Thus, the interaction of ${ }^{129} \mathrm{Xe}$ gas with the surface of the samples leads to changes in the spectral parameters which are used to probe surface and pore properties of the investigated material. This highly sensitive method enables the use of very low $\mathrm{Xe}$ concentrations where the contribution of $\mathrm{Xe}-\mathrm{Xe}$ interactions to the observed chemical shift $\delta$ is negligible and it exclusively reflects the interaction of the gas with the surface of the sample [60].

In order to obtain an overview of the possible adsorption sites and pore structures, single-pulse $\mathrm{HP}{ }^{129} \mathrm{Xe}$ experiments were performed with the diatomite samples. The CD sample does not show any experimental hint for interaction with Xe. Considering the results from the XRD measurements, the pore space is filled with impurities which in large part consist of metal oxides such as $\mathrm{Fe}_{2} \mathrm{O}_{3}$, which would suggest that these impurities block the voids, thus preventing $\mathrm{Xe}$ from entering the pores. However, $\mathrm{N}_{2^{-}}$ sorption data show the presence of a porous system with high surface area that can be explained with the contribution of the inner surface area of the metal oxide impurities. With this information it seems reasonable to assume that the Xe gas enters the pore space, however the paramagnetic iron centers lead to a fast relaxation of the gas thus making the observation of the signal impossible.

For PD, one adsorbant peak appears at $4 \mathrm{ppm}$, which can be attributed to Xe inside silanol-pores (Fig. 9a). The appearance of this peak verifies the loss of the metals (e.g. $\mathrm{Ca}, \mathrm{Ti}, \mathrm{Fe}$, etc.) during purification [i.e. four times acidwashing process of $\mathrm{CD}$ with $\mathrm{HCl}$ (aq.)] as shown in the $\mathrm{XRF}$ analyses. For thermally treated and methylated samples, the Xe-signal appears at slightly higher chemical shifts, which is shown exemplarily in Fig. 9b. As thermal treatment removes the physisorbed and hydrogen-bonded water at the surface of the pores [2,3], the pore space becomes less polar. This improves the Xe-surface interaction resulting in a higher chemical shift values although the average pore diameter does not change significantly [61]. Beside this signal, the spectra of all PD-T-M samples show another broad peak of adsorbed Xe with low intensity (Fig. 9b). It is assigned to Xe in methylated cavities, however, the low intensity of the signal and the slight chemical shift difference to the signal of $\mathrm{Xe}$ in silanolpores suggest that the methylation was only achieved to a limited degree. These findings are also supported by the previously shown results from FTIR, TGA, rehydration tests, and contact angle measurements.

Moreover, VT-NMR experiments were carried out for $\mathrm{PD}-600-\mathrm{M}$ in a temperature range from 293 to $253 \mathrm{~K}$ (Fig. 10).

The spectra show the typical deshielding of the peaks of adsorbed Xe with decreasing temperatures, as a lower temperature slows down the movement of the gas atoms and increases the number of Xe atoms in the pores and the residence time inside the void $[62,63]$. Thus, the linewidth of the signals at lower temperatures is related to the pore 
Fig. 6 TGA curves of PD and two PD-T-M samples

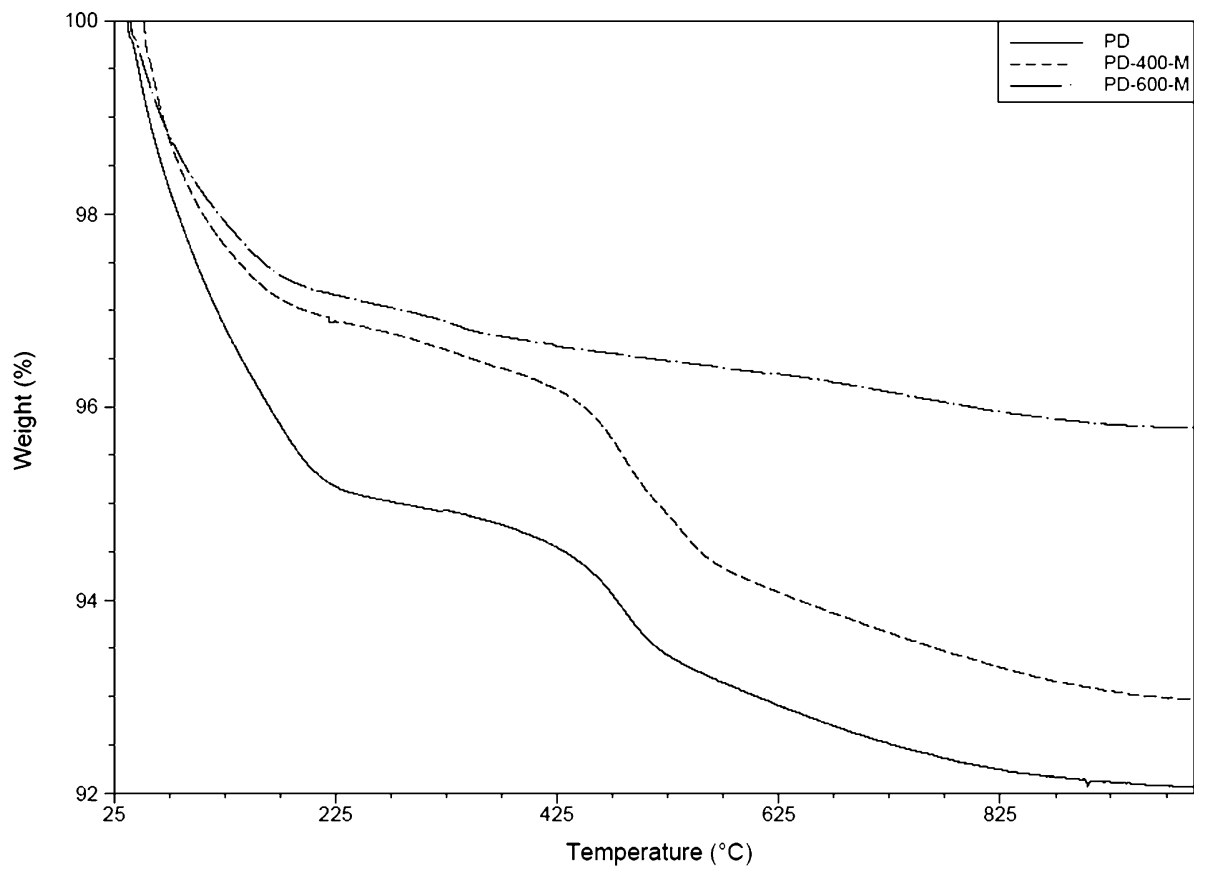

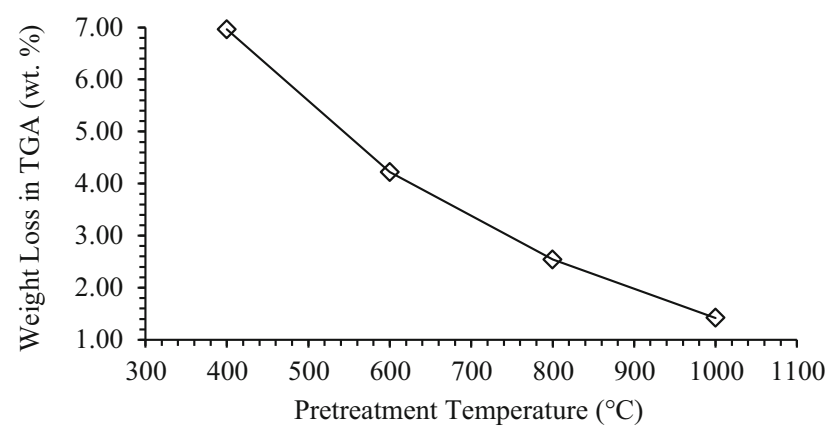

Fig. 7 Weight loss of PD-T-M samples in TGA (weight loss of PD: $7.88 \mathrm{wt} \%)$

Table 3 Contact angles of glycerin drops over pelletized silylated samples

\begin{tabular}{lc}
\hline Sample & Contact angle $\left({ }^{\circ}\right)^{\mathrm{a}}$ \\
\hline PD & $40 \pm 2$ \\
PD-400-M & $76 \pm 5$ \\
PD-600-M & $112 \pm 2$ \\
PD-800-M & $111 \pm 5$ \\
PD-1000-M & $100 \pm 2$ \\
\hline
\end{tabular}

${ }^{a}$ Average of at least 8 repetitions

uniformity (in case there is no chemical shift anisotropy present) [64]. The linewidth of the signal attributed to Xe in the non-methylated pores increases with lower temperature and at $253 \mathrm{~K}$ an additional shoulder occurs. This
Fig. 8 Projected drop of glycerin over pelletized PD- $T$-M samples. a PD-400-M, b PD600-M, c PD-800-M, and d PD$1000-\mathrm{M}$ (a)

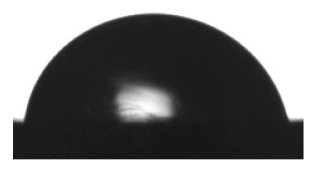

(b)

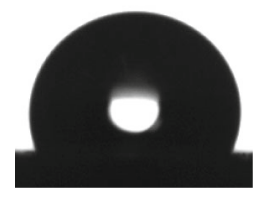

(c)

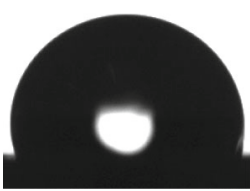

(d)

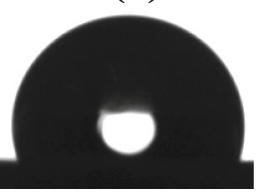




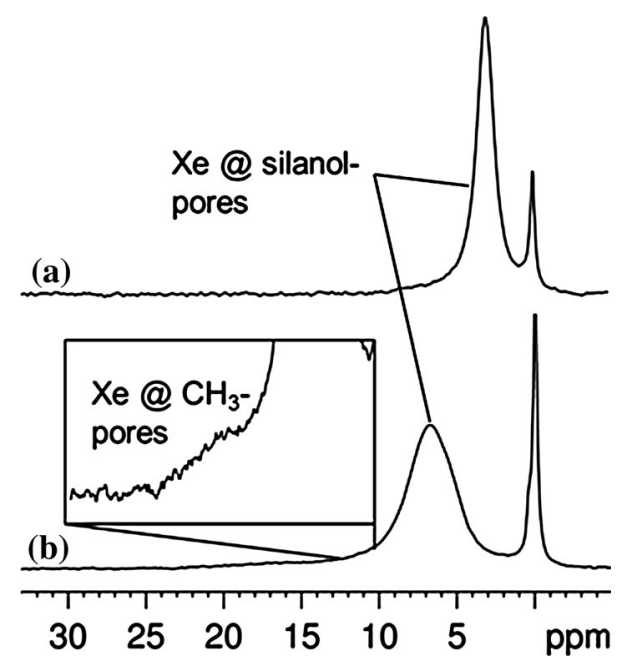

Fig. 9 Single-pulse HP ${ }^{129} \mathrm{Xe}$ NMR spectra of a PD and b PD-600-M (16 scans)

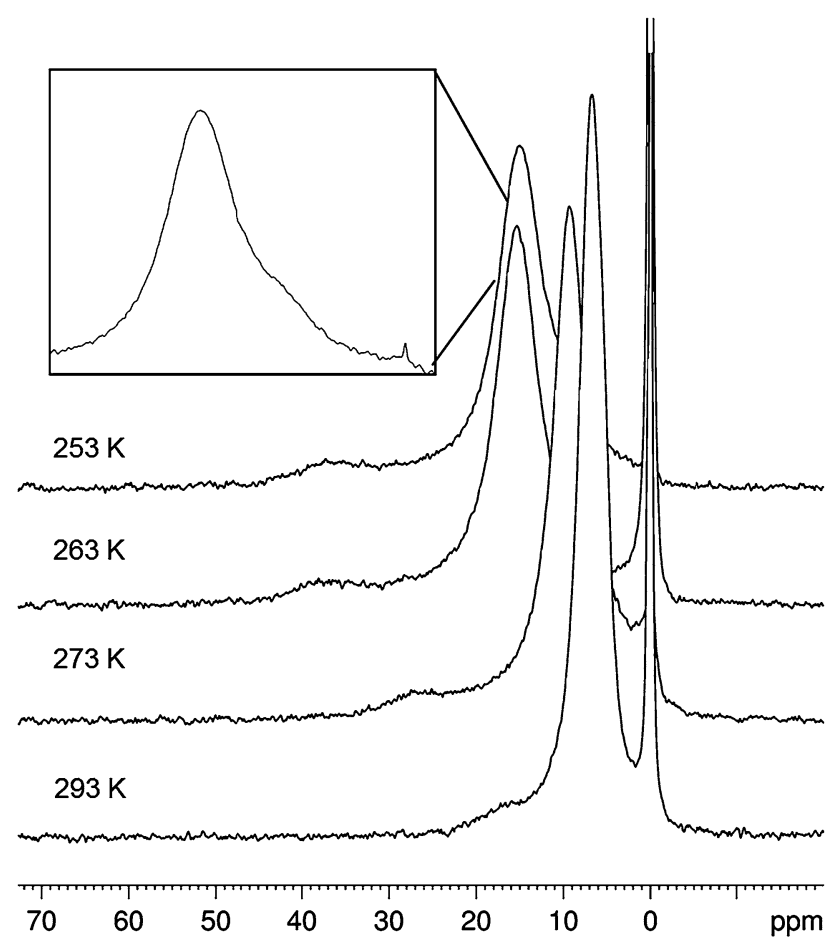

Fig. 10 VT- ${ }^{129} \mathrm{Xe}-\mathrm{NMR}$-spectra of PD-600-M

implies that there are different types of adsorption places or pore structures in the silanol-pores. At higher temperatures, this heterogeneity is averaged out by the fast motion of the Xe compared to the NMR-time scale. Additionally, the broad linewidth of the signal indicates a heterogeneous pore space, i.e. the wall coverage with methyl-groups is not uniformly for all methylated pores.

Finally, for PD-600-M were recorded ${ }^{129} \mathrm{Xe}-{ }^{129} \mathrm{Xe}-$ EXSY spectra with different mixing times, varied from 20 to $40 \mathrm{~ms}$. The exchange peaks between the free gas appeared at mixing times $>20 \mathrm{~ms}$, whereby the exchange between the methylated pores and the silanol pores just appeared for mixing times longer than $35 \mathrm{~ms}$ (Fig. 11). The asymmetry of the diagonal peak attributed to Xe inside the silanol-pores also shows the heterogeneity of this adsorption space which was identified in the VT-NMR spectra. An exchange between the free gas and the methyl pores was not observed at all.

The different intensities of the cross peaks are a characteristic feature of HP-Xe EXSY spectra. Due to the interaction with the pore walls, Xe inside the pores relaxes faster than in the free gas leading to a lower intensity of the exchange peaks right-handed from the diagonal of the spectrum which represent the backward exchange. Additionally the continuous-flow conditions prevent a steadystate adsorption which might influence the exchange rates [65].

The mixing time of the exchange between the two pore types is normally characteristic for interparticle exchange processes which means that silanol- and $\mathrm{CH}_{3}$-pores would be located at different particles of the heterogeneous diatomite mixture. However, we reject this assumption as it implies that $\mathrm{CH}_{3}$-pores are accessible for the free gas as well thus giving a corresponding exchange peak in a similar mixing time as the exchange between the gas and the silanol-pores occurs. Additionally, this interparticle exchange would take place via the free gas from the interparticle gas phase so corresponding exchange patterns and peak intensities should be observable in the spectra.

However, the absence of a peak arising from the gas/ $\mathrm{CH}_{3}$-pore exchange leads to the assumption that the gas

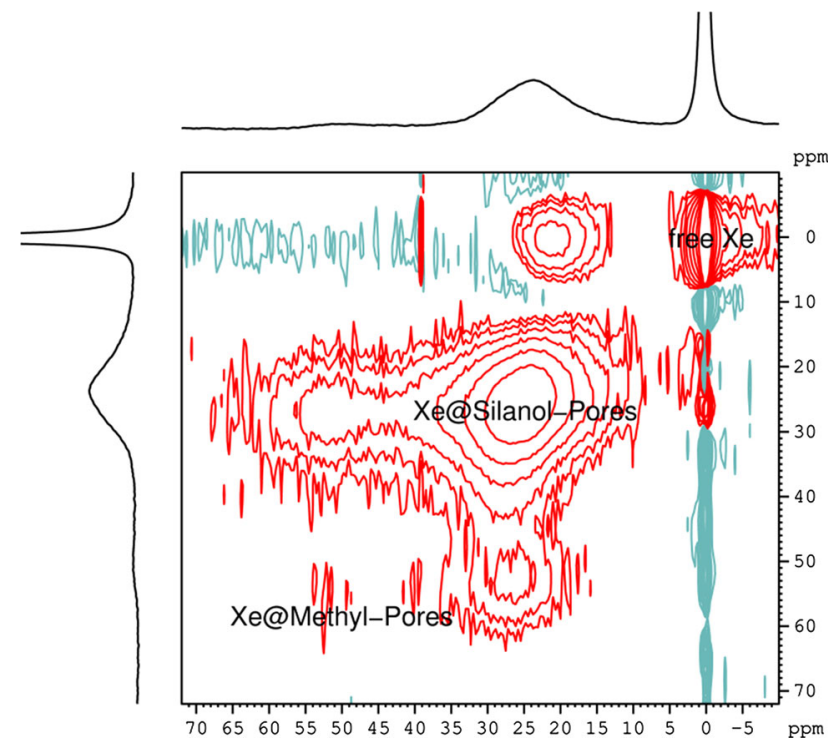

Fig. $11{ }^{129} \mathrm{Xe}-{ }^{129} \mathrm{Xe}-\mathrm{EXSY}$ NMR spectrum of PD-600-M (mixing time: $35 \mathrm{~ms}$ ) at $273 \mathrm{~K}$ 
diffuses into the material via the silanol-pores and is distributed to the methylated samples from there. Continuatively, it is tempting to conclude that the methylation procedure occurred in the pores inside the diatomite particles which are not as easily accessible for the gas as the silanol-pores at the surface and outer spheres.

\section{Conclusions}

A complete study of Costa Rican diatomite silylation with TMCS is presented. The purification process used for crude diatomite and the following thermal treatments and reactions with TMCS in toluene under inert atmosphere allowed to obtain properly silylated materials. The modified diatomite samples have been studied in detail using a complement of instrumental analyses such as $\mathrm{HP}{ }^{129} \mathrm{Xe}$ NMR, FTIR, XRD, SEM, TGA, contact angle measurements, and rehydration tests. XRD and SEM analyses showed that there is no difference in the overall structure of PD- $T$ samples and their corresponding PD- $T$-M products. HP ${ }^{129}$ Xe NMR, FTIR, TGA, rehydration tests, and contact angle measurements evidence a particle modification due to $\mathrm{Si}\left(\mathrm{CH}_{3}\right)_{3}$-groups grafted to the surface, which increases for higher pretreatment temperatures due to the presence of more isolated silanol groups. These results provide valuable information about the silylation of diatomite with TMCS, and also can be useful for modifications using different modifiers that can be achieved in a similar way.

Acknowledgments The authors thank the Vicerrectoría de Investigación (Grant: 115-A9-062) and the Sistema de Estudios de Posgrado of the Universidad de Costa Rica for supporting the research reported in this article. Thanks are also given to Claudia Chaves for her support with the SEM analyses, to Jorge Salazar for performing the TGA analyses, to Dr. Matthias Findeisen for technical support during the NMR experiments, and to Prof. W. D. Einicke for the BET analyses. Prof. Stefan Berger is acknowledged for helpful discussions. Thanks are also given for the valuable comments made by the reviewers.

\section{References}

1. E.F. Stoermer, J.P. Smol, The Diatoms: Applications for the Environmental and Earth Sciences (Cambridge University Press, Cambridge, 2001), pp. 436-443

2. P. Yuan, D. Yang, Z. Lin, H. He, X. Wen, L. Wang, F. Deng, J. Non-Cryst. Solids 352, 3762 (2006)

3. P. Yuan, D.Q. Wu, H.P. He, Z.Y. Lin, Appl. Surf. Sci. 227, 30 (2004)

4. U.S Department of the Interior, U.S. Geological Survey, Mineral Commodity Summaries 2014 (U.S. Geological Survey, Virginia, 2014), p. 53

5. A. Michels, Rev. Biol. Trop. 46, 143 (1998)

6. A. Alfaro, Ciencia y Tecnología 25, 83 (2007)

7. K.R. Engh, Diatomite, in Kirk-Othmer Encyclopedia of Chemical Technology (Wiley, New York 2014), pp. 1-11. doi:10.1002/ 0471238961.0409012005140708.a01.pub2
8. J.X. Lin, S.L. Zhan, M.H. Fang, X.Q. Qian, J. Porous Mater. 14, 449 (2007)

9. M. Sakuma, S. Hori, T. Hayashida, S. Mayama, K. Umemura, J. Porous Mater. 20, 961 (2013)

10. J.P. Berrangé, S.J. Mathers, Rev. Geol. Am. Central 11, 85 (1990)

11. S. Mathers, Rev. Geol. Am. Central 10, 3 (1989)

12. Instituto Geológico y Minero de España, Diatomita y Trípoli (Instituto Geológico y Minero de España, Madrid, 2012), p. 4. http://www.igme.es/PanoramaMinero/Historico/2012/diatomita 12.pdf

13. K.K. Unger, Porous Silica: Its Properties and Use as Support in Column Liquid Chromatography (Elsevier Scientific Publishing Company, Amsterdam, 1979), pp. 57-83

14. L.T. Zhuravlev, Colloid. Surface A 173, 1 (2000)

15. T. Takei, K. Kato, A. Meguro, M. Chikazawa, Colloid. Surface A 150, 77 (1999)

16. N.R.E. Impens, P. van der Voort, E.F. Vansant, Micropor. Mesopor. Mater. 28, 217 (1999)

17. S. Ek, A. Root, M. Peussa, L. Niinisto, Thermochim. Acta 379, $201(2001)$

18. J.B. Peri, A.L. Henseley Jr., J. Phys. Chem. 72, 2926 (1968)

19. R.K. Iler, The Chemistry of Silica: Solubility, Polymerization, Colloid and Surface Properties, and Biochemistry (Wiley, New York, 1979), pp. 622-729

20. D.W. Sindorf, G.E. Maciel, J. Am. Chem. Soc. 103, 4263 (1981)

21. J.W. Goodwin, R.S. Harbron, P.A. Reynolds, Colloid Polym. Sci. 777, 766 (1990)

22. P. Van Der Voort, I. Gillis-D'Hamers, E.F. Vansant, J. Chem. Soc. Faraday Trans. 86, 3751 (1990)

23. P. Van Der Voort, E.F. Vansant, J. Liq. Chromatogr. Relat. Technol. 19, 2723 (1996)

24. P.K. Jal, S. Patel, B.K. Mishra, Talanta 62, 1005 (2004)

25. A.V. Rao, S.S. Latthe, S.L. Dhere, S.S. Pawar, H. Imai, V. Ganesan, S.C. Gupta, P.B. Wagh, Appl. Surf. Sci. 256, 2115 (2010)

26. T. Deschner, Y. Liang, R. Anwander, J. Phys. Chem. C 114, 22603 (2010)

27. A.M. Fidalgo, L.M. Ilharco, Micropor. Mesopor. Mat. 158, 39 (2012)

28. P. Huttenloch, K.E. Roehl, K. Czurda, Environ. Sci. Technol. 35, $4260(2001)$

29. X. Li, C. Bian, W. Chen, J. He, Z. Wang, N. Xu, G. Xue, Appl. Surf. Sci. 207, 378 (2003)

30. X. Qi, M. Liu, Z. Chen, R. Liang, Polym. Adv. Technol. 18, 184 (2007)

31. X. Li, X. Li, G. Wang, Mater. Chem. Phys. 102, 140 (2007)

32. I. Ruggiero, M. Terracciano, N.M. Matcucci, L. De Stefano, N. Migliaccio, R. Tatè, I. Rendina, P. Arcari, A. Lamberti, I. Rea, Nanoscale Res. Lett. 9, 1 (2014)

33. N.M. Oliveira, R.L. Reis, J.F. Mano, A.C.S. Appl, Mater. Interfaces 5, 4202 (2013)

34. P. Yuan, D. Liu, D. Tan, K. Liu, H. Yu, Y. Zhong, A. Yuan, W. Yu, H. He, Micropor. Mesopor. Mat. 170, 9 (2013)

35. M. Aivalioti, P. Papoulias, A. Kousaiti, E. Gidarakos, J. Hazard. Mater. 207-208, 117 (2012)

36. M. Aivalioti, I. Vamvasakis, E. Gidarakos, J. Hazard. Mater. 178, 136 (2010)

37. V.I. Lygin, Russ. J. Gen. Chem. 71, 1368 (2001)

38. Q. Zeng, J.F. Stebbins, A.D. Heaney, T. Erdogan, J. Non-Cryst. Solids 258, 78 (1999)

39. P. Yuan, H.P. He, D.Q. Wu, D.Q. Wang, L.J. Chen, Spectrochim. Acta A 60, 2941 (2004)

40. B. Humbert, J. Non-Cryst, Solids 191, 29 (1995)

41. C.E. Bronnimann, R.C. Zeigler, G.E. Maciel, J. Am. Chem. Soc. 110, 2023 (1988)

42. A. Tuel, H. Hommel, A.P. Legrand, Langmuir 6, 770 (1990) 
43. C.C. Liu, G.E. Maciel, J. Am. Chem. Soc. 118, 5103 (1996)

44. A.P. Legrand, H. Hommel, J.B. dEspinose de la Caillerie, Colloid Surface A 158, 157 (1999)

45. H. Günther, S. Oepen, M. Ebener, V. Francke, Magn. Reson. Chem. 37, S142 (1999)

46. F. Garbassi, L. Balducci, P. Chiurlo, L. Deiana, Appl. Surf. Sci. 84, 145 (1995)

47. F. Bauer, A. Freyer, H. Ernst, H.-J. Gläsel, R. Mehnert, Appl. Surf. Sci. 179, 118 (2001)

48. S. Azizi, T. Tajouri, H. Bouchriha, Polymer 41, 5921 (2000)

49. H. Aderdour, A. Bentayeb, A. Nadiri, A. Ouammou, J.-C. Sangleboeuf, A. Lucas-Girot, C. Carel, J. Phys. IV 123, 361 (2005)

50. K. Rangsriwatananon, A. Chaisena, C. Thongkasam, J. Porous Mater. 15, 499 (2008)

51. O.R. Lazutkina, A.K. Kazak, A.A. Temereva, S.O. Nedopolz, Glass Ceram. 63, 97 (2006)

52. H. Mohamedbakr, M. Burkitbaev, Open Mineral. J. 3, 12 (2009)

53. W. Tsai, C. Lai, K. Hsien, J. Colloid Interface Sci. 297, 749 (2006)

54. S. Nenadovic, M. Nenadovic, R. Kovacevic, L. Matovic, B. Matovic, Z. Jovanovic, J.G. Novakovic, Sci. Sinter. 41, 309 (2009)
55. W. Xiong, J. Peng, Water Res. 42, 4869 (2008)

56. Y. Al-Degs, M.A.M. Khraisheh, M.F. Tutunji, Water Res. 35, 3724 (2001)

57. O. Şan, R. Gören, C. Özgür, Int. J. Miner. Process. 93, 6 (2009)

58. X.S. Zhao, G.Q. Lu, A.K. Whittaker, G.J. Millar, H.Y. Zhu, J. Phys. Chem. B 101, 6525 (1997)

59. X.S. Zhao, G.Q. Lu, J. Phys. Chem. B 102, 1556 (1998)

60. I.L. Moudrakovski, V.V. Terskikh, C.I. Ratcliffe, J.A. Ripmeester, L. Wang, Y. Shin, G.J. Exarhos, J. Phys. Chem. B 106, 5938 (2002)

61. V.V. Terskikh, I.L. Moudrakovski, S.R. Breeze, S. Lang, C.I. Ratcliffe, J.A. Ripmeester, A. Sayari, Langmuir 18, 5653 (2002)

62. A. Nossov, E. Haddad, F. Guenneau, A. Galarneau, F. Di Renzo, F. Fajula, A. Gédéon, J. Phys. Chem. B 107, 12456 (2003)

63. S. Huang, C. Huang, W. Chen, X. Sun, X. Zeng, H. Lee, J.A. Ripmeester, C. Mou, S. Liu, J. Phys. Chem. B 109, 681 (2005)

64. Y. Mao, M. Song, R. Hopson, N.K. Karan, P.R. Guduru, L. Wang, Energy Fuels 30, 1470 (2016)

65. S. Anala, G.E. Pavlovskaya, P. Pichumani, T.J. Dieken, M.D. Olsen, T. Meersmann, J. Am. Chem. Soc. 125, 13298 (2003) 